\title{
O processo diagnóstico das psicopatas do Hospital Nacional de Alienados: entre a fisiologia e os maus costumes (1903-1930)
}

\section{The process of diagnosing psychopatic women in the National Mental Hospital: between physiology and bad costums (1903- 1930)}

\section{Cristiana Facchinetti*}

Fundação Oswaldo Cruz - FIOCRUZ, Rio de Janeiro, RJ, Brasil

\author{
Priscila Céspede Cupello** \\ Fundação Oswaldo Cruz - FIOCRUZ, Rio de Janeiro, RJ, Brasil
}

\begin{abstract}
RESUMO
Este trabalho é parte de um projeto de pesquisa em andamento que investiga a construção das categorias de normalidade e anormalidade para mulheres nas práticas discursivas de psiquiatras e eugenistas brasileiros, entre 1903 e 1930. Este artigo discute a paulatina substituição do diagnóstico de histeria pelo de psicose maníaco-depressiva dos prontuários de mulheres do principal hospital psiquiátrico do (antigo) Distrito Federal. Tal mudança aponta a hegemonia das teorias organicistas alemãs entre as décadas de 1920 e 1930. Demonstra-se então que a mudança nosográfica não promoveu diferença efetiva quer na interpretação, quer na consequente conduta médica frente aos comportamentos considerados, à época, socialmente desviantes. Para a análise, utilizam-se artigos médicos publicados em revistas especializadas e em jornais de grande circulação na cidade do Rio de Janeiro, além de casos clínicos retirados dos Livros de Observações Clínicas do Pavilhão de Observações do Hospital Nacional.
\end{abstract}

Palavras-Chave: História da psiquiatria, Brasil, Gênero, Loucura.

\begin{abstract}
This paper is part of an ongoing research project on Brazilian psychiatrists' and eugenicists' discursive practices between 1903 and 1930 that investigates the construction of normality and abnormality categories for women. It discusses the gradual replacement of the diagnosis of hysteria by maniac-depressive psychosis in women's medical records of the main psychiatric hospital in Brazil's (former) Federal District. The change indicates the dominance of German organicistic theories between the twenties and thirties. It then demonstrates that the nosographic change hasn't made an effective difference, at the time, neither in the interpretation nor on the consequent medical conduct to the considered socially deviant behaviors. For the analysis there were used medical articles published in specialized journal as well as in large circulation newspapers in the city of Rio de Janeiro, besides clinical cases excerpted from the Clinical Books of Observations Pavilion of the National Hospital.

Keywords: History of Psychiatry, Brazil, Gender, Madness.
\end{abstract}


O exame de documentos clínicos pertencentes ao Pavilhão de Observações do Hospital Nacional de Psicopatas (acervo IPUB/UFRJ) ${ }^{1}$, bem como a análise de descrições dos estados psicopatológicos em revistas especializadas, permitem-nos demonstrar como a circunscrição de um diagnóstico e de seu tratamento é instruída por sinais e sintomas variáveis e instáveis e por códigos sociais de uma determinada sociedade e contexto (BERRIOS, 2008). Assim, este artigo utiliza esse tipo de fonte primária para investigar o processo pelo qual a histeria foi paulatinamente retirada do Hospital Nacional, enquanto um crescente número de mulheres passara a ser internado sob o diagnóstico de psicose maníaco-depressiva. As fontes foram levantadas junto aos Livros de Observação do Hospital (IPUB/UFRJ) e foram selecionadas aquelas consideradas qualitativamente exemplares das características prevalentes em termos de diagnósticos, sintomas e sinais no período (cf. PEREIRA, 2006)

O recorte temporal circunscreve o período em que Juliano Moreira ${ }^{2}$ esteve à frente do Hospício Nacional e da Assistência a Alienados, entre os anos de 1903 e 1930. Neste período, a psiquiatria kraepeliana se tornou hegemônica no Hospício Nacional, que até então havia sido norteado pelos referenciais alienistas franceses. Além de fundamental para a institucionalização da psiquiatria local, o momento histórico era de grandes mudanças nos costumes, uma "época de anarquia", de "crises da nascente República" e de "agitações das ruas da capital" (LEMOS apud NEVES, 2010, p. 294308).

O referencial teórico proposto apóia-se em Michel Foucault (2004), quando este sublinha a ausência de uma essência da loucura. Para o autor, cada sociedade criou, inventou e/ou resignificou a insânia a sua própria maneira, de modo que o discurso do encarceramento terapêutico do indivíduo considerado "louco" foi uma estratégia discursiva que somente ganhou estatuto de verdade na história das sociedades modernas (FOUCAULT, 1986). Assim, conforme o saber psiquiátrico se legitimou como verdadeiro no lugar de tantos outros possíveis, é que a figura do psiquiatra e de seu principal instrumento terapêutico, o hospício, passaram a ser considerados como necessários (FOUCAULT, 1997).

Esta compreensão de loucura também está apoiada em Rosenberg (1992), para quem a doença só passa a existir no momento em que ela é nomeada, ou seja, significada. É somente quando um grupo de médicos-psiquiatras dá nomes às "coisas", quando eles a valoram e criam um conceito a respeito, que a sociedade mais ampla pode se apropriar desse vocabulário científico e criar novas relações sociais. Como nos afirma Rosenberg (1992, p. 306, trad. nossa), "concepções de doenças implicam, constrangem e legitimam comportamentos individuais e políticas públicas". Isso significa dizer que, ao pensarmos na construção de uma verdade da loucura enquanto 
doença mental, consideramos que esta não circula apenas no campo profissional; antes, invade também os mais diversos espaços sociais (FOUCAULT, 1997). Em decorrência da compreensão da loucura como doença, as famílias passam a considerar que seus membros loucos devem ser internados em asilos ou que, em caso de crises e atos que envolvam alucinações e delírios, os indivíduos devem ser vistos como portadores de uma doença; é dessa maneira que decorrem os debates sobre o tema em jornais e revistas, etc. (cf. FACCHINETTI et al., 2010b, p. 733-768).

É a partir do a priori dado por Foucault e Rosenberg que tomamos a leitura conceitual e histórica de German Berrios (2008) e demonstramos, como veremos a seguir, que sinais e sintomas variáveis, contextuais e históricos são utilizados seja para justificar a doença de ordem moral, seja para a doença de ordem orgânica, ou mesmo para justificar a entrada ou a saída de um paciente do hospício.

\section{Da loucura à doença mental}

Segundo Gonçalves (2008), a compreensão da loucura como alienação teve início no Brasil na primeira metade do século XIX, tendo como uma de suas consequências a fundação do Hospício Pedro II e a preocupação com o tratamento e cura de alienados. Já na segunda metade do XIX, o processo de organização, sistematização e institucionalização do alienismo no país foi intensificado, especialmente após a criação, no fim do século XIX, da Cadeira de Moléstias Mentais na Faculdade de Medicina do Rio de J aneiro (ESPÍ RITO SANTO et al., 2005; VENANCIO, 2003). ${ }^{3}$

No início do século XX, o tratamento desenvolvido pelos psiquiatras nas instituições asilares era apoiado nas teorias alienistas francesas, principalmente (ENGEL, 2001; MACHADO, 1978). Todavia, ao longo das três primeiras décadas do $\mathrm{XX}$, ocorreu um processo paulatino de afastamento dessa tradição, e sua substituição pelo modelo alemão de psiquiatria, principalmente o desenvolvido por Emil Kraepelin (ENGEL, 2001; MUÑOZ, 2010) ${ }^{4}$, considerado mais de acordo com os ideais cientificistas da época. Este parecia prometer soluções para os problemas tão enfatizados nos relatórios dos primeiros anos do século XX, que ressaltavam a falta de eficiência do asilo (cf. SEABRA, 1903).

Apesar das mudanças teóricas e técnicas, as críticas acerca da pouca cientificidade da psiquiatria, da pouca eficiência dos tratamentos e da necessidade de re-internações continuaram a se fazer ouvir, dez, vinte, trinta anos depois. Os ecos dessas críticas eram, por conseguinte, frequentes também nos Relatórios Ministeriais ao longo das décadas: 
Não é possível com o elevado número de doentes, com o escasso pessoal e verbas parcimoniosas, muito aquém das necessidades, transformar este manicômio em um verdadeiro estabelecimento hospitalar, onde o doente deve ser convenientemente observado, vigiado e curado (SANTOS, 1916, p. 74).

O excesso de contingente tantas vezes reclamado, a dificuldade de tratar doentes com tendência à reincidência, como no caso do alcoolismo (cf. FREITAS, 1915, p. 63), bem com os novos padrões de internamento advindos da Clínica de Munique e das colônias de alienados européias, tornaram necessária uma mudança estrutural na Assistência que desse conta da doença mental antes mesmo de ela chegar acontecer: a prevenção foi se tornando a grande chave para o sucesso dos tratamentos. Tal mudança se estabeleceu efetivamente a partir da nova Lei de $1927 . .^{5}$ Com ela, ampliou-se o escopo dos cuidados médicos-mentais, que passou a investir seus esforços na população, ou como aparece no decreto nos "psicopatas, alienados ou não" (decreto n. 17.805). A partir de então, estabeleceu-se como competência da Assistência aos Psicopatas:

\footnotetext{
Estudar os problemas relativos á higiene mental e á psicofisiologia normal ou mórbida, aplicadas ás diversas atividades sociais, no intuito de fixar os meios mais eficazes de organizar a profilaxia das perturbações nervosas e mentais" (decreto n. 17.805 de 23/05/1927).
}

Assim, a aproximação com a psiquiatria kraepeliana, associada ao aumento de importância dada pelo Estado à higiene mental ${ }^{6}$, permitiu aos psiquiatras da Assistência ampliarem suas estratégias discursivas acerca da sua participação e responsabilidade frente às questões da saúde da população, passando a enfatizar não apenas a internação, mas também a prevenção, pensada então como capaz de evitar o excesso de reclusões e, ainda mais, do próprio adoecimento. Compreendiam assim participar do incentivo, da manutenção e da construção da normalidade, bem como da regeneração da população local (NUNES, 2010, p. 386). ${ }^{7}$

\section{A normalidade e a Patologia: jogo de espelhos}

Por meio da análise de alguns artigos médicos, é possível constatar a retórica da prevenção acoplada à construção da normalidade enquanto um bem social necessário para uma sociedade bem desenvolvida. ${ }^{8}$ É importante ressaltar, portanto, que a construção da normalidade feminina apresenta-se como um saber que afirma o papel da mulher, ao mesmo tempo em que cria o que é ser esta "mulher" (SCOTT, 1994). Assim, conforme os médicos investigavam o corpo feminino, partilhavam de noções, conceitos e valores 
socialmente compartilhados e deram a estes o peso de fato científico que, como tal, foi naturalizado e não mais questionado.

Nessa perspectiva, houve todo um empenho da sociedade republicana recém-formada para criar a imagem da cidadã desejável para a vida social, o que emergiu como um valor em si. Isto porque, com as teorias em voga que preconizavam o papel eugênico e higiênico da maternidade, a "má conduta" feminina poderia acarretar desordem social e comprometer a prole, o que se refletiria para toda a sociedade. Como Afirmou Renato Kehl, voz bastante recorrente do empenho médico e eugênico de "salvar a Raça" (KEHL, 08/02/1926) e "pai da eugenia no Brasil", no artigo "A Inteligência da Mulher":

a mulher tem o cérebro idêntico ao do homem e poderá desdobrar o seu psiquismo na mesma proporção. Melhor será que não o faça: a espécie humana seria prejudicada se todas as mulheres quisessem intelectualizar-se" (KEHL, 30/06/1926).

Além dos eugenistas, os psiquiatras também participaram do processo de modelagem dessa cidadã republicana exemplar, cunhada por Júlio Porto-Carrero ${ }^{10}$ como a "esposa-mãe", "o tipo completo da mulher normal" (PORTO-CARRERO, 1930a, p. 91).

Entretanto, considera-se que ao circunscrever as características exigidas para a cidadã brasileira normal, estava-se, há um só tempo, traçando também o perfil do anormal e do patológico como seu outro especular (FOUCAULT, 1987; 2001). É esse detrito, que retorna, que insiste e que ameaça o futuro da civilização por seus desvios, que deve ser corrigido e tratado por meio da ciência e das tecnologias (CANGUI LHEM, 1990, p. 187). Essa era justamente a promessa dos saberes médico-psicológicos para a sociedade. Mas por que a questão da mulher normal se torna tão fundamental neste período histórico na capital do país?

O processo biopolítico (FOUCAULT, 2008) no Brasil se organizou com mais rigor a partir do projeto republicano. Assim, no início do século $X X$, o Rio de Janeiro sofreu várias transformações sociais em meio à explosão de processos de urbanização, industrialização, de imigrações, com aumento nos níveis de criminalidade, corrupção, doenças, emergência de um proletariado urbano de ex-escravos, etc. (BENCHIMOL,1990; BULMER-THOMAS, 2005).

No que diz respeito às mulheres, o modelo normatizado e disciplinarizado pela medicina do corpo feminino desde o século XVIII, marcado pela maternidade e cuidado das proles (DORLIN, 2006), começou a ser ameaçado pelos ventos da modernização. Não eram mais apenas as ex-escravas e empregadas de manufaturas que tinham acesso às ruas da cidade, mas as "boas moças de família" também passaram a circular em festas, lojas e teatros (BORELLI, 1999; MALUF; MOTT, 1998). Mulheres de classe média começavam a 
ter acesso a estudo e a trabalho fora de casa, constituindo um grupo de professoras, enfermeiras, etc. (HAHNER, 2003; SINGER, 1980). Nos anos de 1920 começavam também as lutas pelos direitos das mulheres, como o que ocorreu com a Federação Brasileira pelo Progresso Feminino (FBPF), criado em 1922, e que em 1932 participou da conquista do direito de voto da mulher, concedido em decreto-lei por Vargas (BORELLI, 1999; MACEDO, 2000). Foi também neste período que mulheres de esquerda e artistas ligadas à vanguarda estética romperam com tabus e preconceitos, como no caso de Tarsila do Amaral (ARACY, 2003) e de Pagu (PONTES, 2006). Tal dissolução de costumes, entretanto, não só contrariava o papel do gênero feminino tradicional, mas passava a ser compreendida então como um risco à saúde. Oda, Banzato e Dalgalarrondo ressaltam que os psiquiatras brasileiros daquele período no geral concordavam inteiramente com a afirmação repetida por quase todos os alienistas influentes depois de Esquirol, de que as "exigências da vida civilizada, a superpopulação nas grandes cidades, a dissolução dos costumes, a pobreza urbana, o esgotamento físico e mental dos tempos modernos seriam causas desencadeantes de um suposto aumento nas taxas de doenças mentais" (apud ODA; PICCININI, 2005, p. 790).

Assim, as agitações da cidade, a saída de casa, o perambular pelas ruas, teatros, avenidas; o trabalho externo, enfim: a modernidade que batia à porta das moças da capital ameaçava a ordem republicana. Esses comportamentos foram interpretados por meio da psicopatologia: e quanto a isso, o risco para a mulher e sua prole era bastante ameaçador.

Um exemplo dessas idéias pode ser encontrado no artigo do psiquiatra Júlio Porto-Carrero. Ele chama atenção para os "terríveis avanços da indústria de eletrodomésticos", que vinham deixando as esposas ociosas em casa, sem precisar confeccionar roupas ou usar seu tempo na faxina (PORTO-CARRERO, 1930b, p. 159). Além disso, afirmava o psiquiatra, com a criação de creches, as mulheres teriam perdido também a função de cuidar da prole. Para ele, a sociedade estaria vivendo um período de crise por conta de tal ociosidade, que instigava o desejo feminino de trabalhar e de se emancipar. Apoiado na teoria da degenerescência, o médico afirmava que tais mudanças nos hábitos sociais seriam determinantes para o desenvolvimento de doenças mentais (PORTO-CARRERO, 1930b, p. 159).

O desejo de trabalhar fora de casa seria, assim, uma "calamidade mental". Afinal, sendo um ente maternal por natureza, a mulher não poderia exercer outra função que não fosse as que lhe cabiam no lar. Assim, Porto-Carrero era categórico ao afirmar que o trabalho externo deveria ser confiado apenas ao homem (idem, p. 159). Para ele, às mulheres cabia à reprodução, visto que seu corpo dava sinais todo mês, com a menstruação, de sua missão materna. Como afirmava no artigo, 
(...) a mulher é o ser por sexual por excelência (...) basta a si mesma para reprodução; ainda na espécie humana é o que maior prazo de vida dedica a essa função. A mulher puramente companheira de trabalho é um ser que mente à sua finalidade (PORTO-CARRERO, 1930b, p. 164).

Outro item fundamental para a construção modelar do cidadão proposto pela medicina mental do período era a instituição matrimonial, que "representa[va] uma etapa superior das relações amorosas", sendo então proclamada como "'garantidora da saúde da humanidade', o melhor remédio para o corpo e para a alma" (MALUF; MOTT, 1998, p. 386).

De fato, o eugenista Kehl, personagem de grande influência nos meios médicos e na divulgação científica do período, no ano de 1926 escreveu no jornal O Globo o artigo intitulado: "Quer Casar? Pois Consulte o Médico Primeiro! O esforço da Eugenia para Salvar a Raça - Como Escolher uma Boa Esposa!", no qual advertia acerca dos perigos da emoção e da impulsividade (como os sentimentos de amor e paixão) na hora de escolher uma esposa. Kehl insistia para que tanto homens quanto mulheres procurassem um médico antes de afirmar qualquer compromisso conjugal, pois só a reprodução planejada poderia interferir no futuro da nação (KEHL, 08/02/1926). Além da reprodução planejada, Kehl demandava que fossem transformados em lei os exames pré-nupciais: segundo ele, a obrigatoriedade desses exames seria uma medida de "ultra-profilaxia racial" (KEHL, 08/02/1926, p. 3). Afirmava ainda que o jornal deveria "perseverar nessa campanha benemérita", para o "progresso do nosso país" (idem, p. 15). Kehl dizia que o dia em que o exame prénupcial fosse transformado em lei seria o "legítimo dia da raça", já que garantiria a saúde dos lares e a "regeneração e defesa da nacionalidade" que se encontravam ameaçados por diversos males, tais como:

(...) casamentos de doentes e tarados, de consanguíneos, além da degeneração causada pelas endemias que a castigam e pelas levas imigratórias constituídas pelo rebotalho heterogêneo que vem complicar, ainda mais, as mazelas de nosso laboratório étnico. (KEHL, 02/03/1926, p. 15)

Entretanto, segundo o médico, havia resistências para estabelecer a prática do exame pré-nupcial pelas mulheres, pois estas não se permitiam examinar por um médico. O grande esforço de Kehl nos jornais era o de demonstrar a importância dos exames, angariar adesão da opinião pública, ratificando a necessidade da prevenção de doenças ou afirmando que se as moças fossem examinadas pelos médicos, poderiam evitar até mesmo o risco de morte em partos ou 
por alguma doença. E já para as jovens de "pudicícia exagerada, não faltariam médicas para o caso". Afinal,

\begin{abstract}
Quantas jovens não garantiriam a sua vida desse modo? Quantas jovens, incapacitadas, temporária ou definitivamente, para um parto natural, não tomariam as suas cautelas, evitando os seus perigos e acidentes mortais? Quantas jovens não se presumiriam de infecções nojentas, infelizmente tão comuns entre jovens pouco escrupulosos? (idem, p. 9)
\end{abstract}

Assim, as preocupações dos psiquiatras e eugenistas com relação à questão da reprodução e da hereditariedade voltavam-se para as mulheres objetivando estratégias para a raça brasileira, para que ela "pudesse alcançar o patamar do moderno e, por conseguinte saudável" (FACCHINETTI; VENANCIO, 2006, p. 153).

\title{
A loucura, o asilo, as mulheres
}

Um lugar de destino de boa parte dos desvios femininos, no período, era o Hospital Nacional. Naquela instituição, as instalações femininas eram divididas em duas grandes seções principais: a Morel (para pensionistas) e a Esquirol (para mulheres mantidas com recursos do Distrito Federal). ${ }^{11}$ Nessas seções era possível encontrar mulheres cujos sinais e sintomas assinalados pelos médicos incluíam comportamentos "desobedientes", "irritáveis", de "sexualidade e desejos excessivos", que não queriam cuidar dos filhos ou dos serviços domésticos, que desejavam trabalhar fora de casa, liam romances ou estudavam em demasia, recusavam a se casar, etc. (cf. PUECH, 1907, p. 352-353; ROXO, 1906, p. 141).

No início do século XX, a histeria era a doença mais presente entre as mulheres internadas no Hospício Nacional, sendo preponderante até aproximadamente o ano de 1920. Antônio Austregésilo ${ }^{12}$, médico do hospício entre os anos de 1904 e 1910, atestava então que a histeria era a grande patologia feminina no hospício, enfatizava e criticava a superabundância sintomática da mesma e sublinhava que a histeria era um "diagnóstico de facilidade, sobretudo em se tratando do sexo feminino" (AUSTREGÉSILO, 1908, p. 52). Dizia ainda que os "casos de afecções nervosas difíceis e insólitas, sobretudo em mulheres", tomavam-se costumeiramente rótulos de histeria (AUSTREGÉSILO, 1908, p. 53).

E quais eram as características dessa doença mental que invadia de tal modo as alas femininas do HNA? O psiquiatra Henrique Roxo ${ }^{13}$, em seu artigo intitulado "Hysteria", publicado nos Archivos Brasileiros de Psychiatria, Neurologia e Sciencias Affins, ${ }^{14}$ afirmou que o sintoma fundamental dessa doença era a "instabilidade". A histeria seria causada pela deterioração social resultante "da educação viciosa, da existência em um meio em que a imaginação é muito excitada, em 
que se vive mais de romances" (ROXO, 1906, p. 141). Em outras palavras, doença que decorria da desordem e degradação social.

\begin{abstract}
Na vida familiar, a cada passo se prepara uma histérica, já concedendo-Ihe a leitura de romances fantásticos, já excitando a sua imaginação com sonhos eróticos, já colocado a vida n'uma contemplação mística que predispõe à histeria (idem).
\end{abstract}

Para Henrique Roxo, as histéricas seriam mulheres vaidosas e teimosas, que sempre tentavam impor as suas vontades e, quando não eram atendidas ou eram contrariadas, se revoltavam. Para ele "a histérica é sempre irritável, porque quer que tudo corra a mercê de seus desejos", sendo "péssima dona de casa" (ROXO, 1906, p. 144). Portanto, as histéricas eram as mulheres que andavam na contramão do modelo ideal de mulher, que seria, segundo o autor, aquela que não alimenta a vaidade, sendo doce, submissa, além de boa mãe e dona de casa.

No artigo publicado, em 1909, intitulado "Hysteria e syndromo hysteroide", o médico brasileiro Antônio Austregésilo, quando se referiu à histeria, chamou-a de "hysteria ou pithiatismo", termo criado pelo médico francês Babinski que considerava a histeria uma doença cuja etiologia estaria exclusivamente ligada à auto-sugestão ou sugestão, e que sua cura seria produzida pela persuasão. De acordo com Trillat:

Dizer a um sujeito 'você está atingido de paralisia' é uma sugestão; dizer-lhe 'sua paralisia é imaginária e pode desaparecer', é persuasão. Dessa luta entre o bom e o mau, procede à definição de histeria: as perturbações histéricas são aquelas passíveis de serem reproduzidas por sugestão e de desaparecerem sob influência exclusiva da persuasão (TRILLAT, 1991, p. 209).

Segundo Michel Foucault, Babinski foi um dos personagens significativos do movimento de "despsiquiatrização" que apareceu logo após a "crise Charcot". ${ }^{15} \mathrm{O}$ que Babinski propôs, nos diz o autor, foi reduzir a doença à sua estrita realidade, o que talvez fosse "apenas a aptidão para se deixar teatralizar: pitiatismo" (FOUCAULT, 1997, p. 52). Segundo Birman (2010, p. 348), as mulheres diagnosticadas como pitiáticas eram consideradas "deslavadamente mentirosas, produzidas pela sugestão e desconstruídas pela persuasão" (BIRMAN, 2010, p. 348). Assim, enquanto para Babinski a histeria não pertenceria à neurologia, sendo puro produto da sugestão (TRILLAT, 1991, p. 209), Charcot defendia que: 
a histeria era uma alteração do sistema nervoso. Teria etiologia hereditária e seria produto de alguma degeneração, podendo ser disparada por traumas e choques mecânicos. Essas alterações nervosas possibilitariam a sugestionabilidade dos histéricos (apud NUNES, 2010, p. 376).

Chamamos atenção para o fato de que Antônio Austregésilo afirmava em seu artigo que o pitiatismo representava uma "psico-nevrose ou como estados psico-nevróticos desenvolvendo-se em um terreno comum a todas as psico-nevroses - o nervosismo" (AUSTREGÉSILO, 1909 , p. 61). Percebemos então uma reunião de enunciados paradoxais ditados pelo médico. De um lado, afirmava que a histeria era produto da sugestão e, portanto, uma afecção psicológica, conforme atestou Babinski; de outro lado, admitia que a histeria era uma psiconeurose, que se desenvolvia a partir de uma grande diátese: o nervosismo, tal como Charcot. Segundo Silvia Nunes, essa reunião de teorias era devido à "impossibilidade de explicar a histeria exclusivamente a partir de uma única vertente, fosse psicológica ou orgânica" (NUNES, 2010, p. 382).

Mas cada vez mais, ao longo da década de 20 do século $X X$, o entendimento da histeria de Charcot foi deixado de lado. O marco dessa mudança pode ser lido no artigo publicado em 1927 nos Archivos Brasileiros de Neuriatria e Psychiatria, quando o psiquiatra Lopes chamou as teorias do francês de "exageradas e dogmáticas", apesar de considerar que elas tenham dominado longamente 0 campo da psiquiatria, segundo ele não só entre os médicos do hospício, "mas também nos mais afamados centros de cultura médica do mundo" (LOPES, 1927, p. 79).

Assim, notamos nos artigos médicos, a partir da década de 20, não só uma crescente crítica às teorias de Charcot, mas também uma mudança na forma da conceituação da mesma, que passa a ser entendida primordialmente a partir das teorias de Babinski. Em consonância com essas teorias, Henrique Roxo esclareceu que a histeria deveria ser entendida como um acometimento psicológico e não biológico, e que "se devia dar mais valor ao papel da emoção a buscar um fundamento anátomo-clínico para a constituição histérica" (ROXO, 1929, p. 15).

$\mathrm{Na}$ medida em que os médicos brasileiros iam mudando da leitura clássica da histeria para as teorias de Babinski ${ }^{16}$, tornou-se necessário rever grande parte dos diagnósticos das internas do Hospital Nacional. De fato, a apropriação dessa verdade sobre a histeria colocava em questão as internações feitas desde a fundação do Hospício, no século XIX, já que o número de histéricas havia sido sempre alto. Ou bem se havia internado mulheres que não precisavam de internação (pois não tinham doença considerada 
orgânica), ou bem elas não haviam sido diagnosticadas adequadamente.

A solução para o problema foi sendo construída ao longo do primeiro quartel do século XX, como nos informam os Relatórios Ministeriais e os Arquivos Brasileiros de Psiquiatria, que apontam para uma separação entre doenças a serem tratadas em asilos e anormalidades a serem tratadas em ambulatórios. Assim, somos informados que em 1914 "casos de epilepsia, de histeria, etc. foram gratuitamente examinados e medicados, poupando assim o Estado das despesas que lhe adviriam com a hospitalização" (SANTOS, 1915, p. 77).

Mas se muitas histéricas passaram a ser tratadas fora do asilo, a ponto do diagnóstico de histeria ao final da década de 1920 não ultrapassar $2 \%$ dos diagnósticos das mulheres no hospício (enquanto que em décadas anteriores chegava a cerca de $40 \%$ dos casos das mulheres internadas, de acordo com pesquisa de Pereira (2006), isso não significa que o hospício tenha evitado o super-povoamento dos pavilhões femininos (cf. CORRÊA, 1912).

Há, isto sim, uma outra ordem curiosa de acontecimentos: o crescimento significativo do número de mulheres diagnosticadas com loucura maníaco-depressiva no hospício, doença descrita pelo psiquiatra alemão Emil Kraepelin, que se aproxima de $28 \%$ (PEREIRA, 2006) na década de 1930. Dentro da maior ala feminina do hospital, a Sessão Esquirol, entre os anos de 1900 a 1910 a loucura maníaco-depressiva representava apenas $3 \%$ dos diagnósticos; ao longo da década de 1920, esta porcentagem cresceu para 16\% (cf. CUPELLO, 2010).

Ao analisar essa mudança, Birman (2010, p. 369) afirma a consolidação do "paradigma teórico de Kraepelin que conduziu o discurso psiquiátrico a diagnosticar com maior frequência a loucura maníaco-depressiva no lugar da histeria". E de fato, nos debruçando sobre artigos científicos do período, encontramos declarações que apontam para essa mudança de raciocínio nosológico:

\begin{abstract}
A escola de psiquiatria nacional, fundada pelo gênio scientifico-philosophico de Juliano Moreira e fecundamente impulsionada pela nova geração de alienistas brasileiros, seguindo a formula kraepelineana, houve por bem alterar e corrigir para psicose maniaco-depressiva muitos desses remotos diagnósticos [de histeria] (LOPES, 1927, p. 79).
\end{abstract}

Segundo Joel Birman (2010), a virada do alienismo francês para a psiquiatria alemã vinha se esboçando desde o artigo publicado em 1905, escrito pelo médico Afrânio Peixoto (1876-1947) em 1905, intitulado "A loucura maníaco-depressiva", evidenciando em suas primeiras páginas a importância de Kraepelin. Anos mais tarde, vemos a adoção pelos médicos brasileiros do modelo nosográfico kraepeliano, com o aumento do número de mulheres diagnosticadas 
com loucura maníaco-depressiva, a partir da verificação de estados mistos de psicose, ou seja, um processo variando entre a mania e a melancolia (PEIXOTO, 1905, p. 33).

$\mathrm{Na}$ descrição da doença, ressaltam alguns aspectos. O doente acometido pela loucura maníaco-depressiva era normalmente um doente hereditário (por estar enquadrado na classificação kraepeliana entre os males congênitos e de ordem da intoxicação interna), marcado, portanto, pela degeneração presente nessas categorias (CAPONI, 2010). De acordo com o psiquiatra Adauto Botelho ${ }^{17}$, a loucura maníaco-depressiva acometeria os pacientes já no meio da vida, quando os doentes apresentavam um comportamento modificado, em que transpareceriam estados isolados, subintrantes, intermitentes, puros ou combinados, de excitação - com "humor alegre", "ideação rápida" e "movimentação exagerada"; ou depressão - com "humor triste", a "ideação lenta" e a "movimentação demorada". Tais estados seriam sucedidos por intervalos de saúde, sem aparente lesão da inteligência (BOTELHO, 1929, p. 106-108).

Foi este o discurso, embasado na psiquiatra alemã, que passou a caracterizar-se pela presença obrigatória de um conjunto de enunciados que, além da descrição sintomática, apontava para outros, marcados pela biomedicina do período e que demonstravam a aproximação da psiquiatria ao campo mais amplo da medicina: aqueles oriundos da anatomia, da bioquímica, da fisiologia e da então recente teoria da hereditariedade (BIRMAN, 2010, p. 348).

Entretanto, cabe-nos aqui perguntar: o quanto representou de diferença no perfil das mulheres essa mudança no quadro nosológico? A loucura feminina mudou? O perfil das pacientes teria mudado? Para nos aproximarmos dessas mulheres que mantiveram as alas femininas do HNA superlotadas, trazemos dois exemplos típicos de loucura feminina retirados do Livro de Observações do Hospital Nacional.

O primeiro caso estudado é o de Paola ${ }^{18}$, de 30 anos. Ela deu entrada no Pavilhão de Observação em 1906, pelas mãos da polícia. Segundo o médico que a observou, Paola havia contado a ele a história de sua crise atual, bem como do que antecedeu essa crise. Relatou então que já casada, havia tido a oportunidade de visitar a família na Europa, deixando seu marido no Brasil. Os problemas começaram nessa viagem a Itália, uma vez que foi então que acabou por ficar sob "tentações diabólicas que, segundo diz, ninguém está livre, quebrou a severidade de sua conduta, faltou aos seus deveres de esposa e, de volta, apresentara-se ao marido grávida de três meses." $\mathrm{Na}$ época, o marido a abandonou "após alguns castigos corporais" (LIVRO DE OBSERVAÇÃO..., 1906).

Ficando sozinha, Paola logo encontrou nova companhia, e se "amasiou" com o novo companheiro. Tudo ia bem até que, algum tempo depois, seu primeiro marido reapareceu com desejo de reatar 
o casamento. Paola quis então se separar do amásio, que se "opôs tenazmente a sua retirada", prendendo-a a força em casa e "maltratando-a cruelmente a pancadas" (LIVRO DE OBSERVAÇÃO..., 1906). Na confusão, a polícia foi chamada a intervir. O delegado, após tomar conhecimento de sua má conduta, resolveu encaminhar Paola ao Hospício, por suspeita de alienação. Tal como podemos antever a partir artigos médicos nas revistas especializadas mostradas no item anterior, a mulher que não desejava ficar ao lado de seu companheiro era vista como suspeita de adoecimento mental e esse era um dos motivos recorrentes de envio de mulheres ao hospício. De acordo com Magali Engel, quando se fala em internação de loucura feminina, o que os laudos e perícias médicas tem em comum é o fato de essas mulheres não cumprirem "adequadamente seus papéis de esposa e mãe" (ENGEL apud NUNES, 2010, p. 383).

Ao chegar ao hospício, o médico constatou inicialmente que Paola era "muito nervosa e extremamente "suscetível a crise violenta, de raiva". Tendo diagnosticado-a como histérica, transferiu-a para a Seção Esquirol, não sem antes ressaltar suas mudanças de humor ao longo daqueles dez dias de avaliação. Após as crises de raiva, Paola tornou-se "sujeita a crises de risos e de prantos não rara". Ressaltase, ainda, que a única medicação indicada em seu prontuário era o "estrato de fluido de maracujá" (LIVRO DE OBSERVAÇÃO..., 1906).

Finalmente, vale ainda chamar atenção para o fato de que Paola fora tratada de forma violenta, mas que esses atos não foram em momento algum questionados, e sim tratados como disciplinadores, além de um direito do homem sobre a mulher. Em outras palavras, uma medida necessária em defesa da honra, "uma punição a uma atitude feminina desviante - adultério, traição, insubordinação - e era uma reação esperada do homem que tinha uma relação com uma mulher infiel." (BORELLI, 1999, p. 95-96).

O segundo caso clínico, com o diagnóstico de loucura maníacodepressiva, é o de Maria Antonia, de 58 anos. Pelas informações retiradas do Livro de Observações Clínicas, sabemos que Maria foi encaminhada pela própria família ao Hospital, dando entrada no Pavilhão de Observação no ano de 1930. O motivo pelo qual seus familiares resolveram interná-la está relacionado à má conduta de Maria. Tal comportamento teve início por ocasião da morte de seu esposo e de um de seus filhos. A partir desse acontecimento, somos informados que: "por dias não mais quis saber da casa, andando de um lado para o outro lado sem destino, falando sem cessar, falando e batendo nas crianças e em si própria". Como sinal de seu adoecimento, o médico que a observou declara ainda que ela "mostra[va]-se abatida, sempre chorosa (LIVRO DE OBSERVAÇÃO..., 1930).

Não sabemos muito mais sobre a história de Maria; em sua papeleta, consta apenas que do Pavilhão de Observação ela foi transferida para 
a seção Esquirol até receber licença requerida por sua família, dois meses depois. Isto significa que embora não tenha sido curada pelos médicos do hospício, ela foi considerada apta a voltar para casa e retomar seu trabalho junto aos filhos pequenos e a sua casa.

Quanto à circunscrição de seu diagnóstico, os documentos clínicos referem-se apenas aos sinais e sintomas de "irritabilidade", "excitação" e "falta de interesse de cuidar dos filhos e da casa", devido ao seu estado "depressivo" (LIVRO DE OBSERVAÇÃO..., 1930). Podemos identificar nela o "estado de melancolia", relatado por Adauto Botelho como:

\begin{abstract}
humor feito de tristeza, de indiferença e de desencorajamento que não condizem com a agressividade, com a iniciativa dos doentes de mania colérica. O melancólico, sobretudo por seu humor, tem aversão por todas as formas de atividade, se desinteressando da ambiência por num isolamento passivo cheio de dificuldade e de coisas negras. Destituído de toda a energia de ação (BOTELHO, 1929, p. 110)
\end{abstract}

Quanto ao seu tratamento, a única menção encontrada foi a da utilização do mesmo "estrato de fluido de maracujá", utilizado com Paola.

Assim, ao compararmos um caso feminino de histeria (de classificação psicodinâmica e moral) da primeira década do século XX com um de loucura maníaco-depressiva (da classificação de cunho organicista) da década de 30, verificamos que a mudança do paradigma teórico modifica as discussões acadêmicas sobre as doenças. Assim, há uma alteração substantiva na compreensão etiológica da doença, assim como no cunho moral ou orgânico da enfermidade (a histeria parece estar marcada pela má educação da jovem, enquanto que a loucura maníaco-depressiva parece estar mais envolvida com glândulas e disfunções hormonais da mulher madura), além de se verificar uma preocupação longitudinal da mesma com o passar dos anos, o que remete a uma história da doença desde os seus primeiros sinais.

Para a vida dessas mulheres, entretanto, suas condutas desviantes foram, em ambos os caso, tratadas igualmente como patológicas e justificaram sua internação em uma instituição asilar, para que pudessem ali ser tratadas e curadas. Assim, Paola e Maria foram internadas na seção Esquirol, tendo como terapêutica, além do medicamento "estrato de fluido de maracujá", o isolamento do asilo, previsto como capaz de acalmar seus ânimos exaltados e trazê-las de volta à consciência de seus papéis sociais. Maria e Paula são exemplos clínicos que se repetem às centenas nos Livros de Observações Clínicas. Nesses casos ressalta-se a importância, dada pelos médicos, ao não cumprimento das obrigações domésticas e 
maternais como sinais e sintomas da insanidade. Portanto, percebemos que a constatação do desvio patológico tornava-se visível no nível dos comportamentos, sendo enfatizado e legitimado pelo não cumprimento dos "deveres" de mãe e esposa, em um momento em que os excessos, os desvios e as transgressões eram tratados como sintomas psicopatológicos

\section{Considerações Finais}

Esse artigo se debruçou sobre o campo de discussões e negociações em que estavam inseridos eugenistas e psiquiatras desde o início da república, quando participavam do processo de delineamento e fixação de padrões e papéis de normalidade, tanto para homens quanto para mulheres. Tais debates se deram em meio à questão mais geral acerca da modernidade e dos obstáculos civilizatórios que os brasileiros precisavam superar em prol do progresso político, econômico e sócio-cultural da nação.

É central neste debate o problema da nação, quando a população passou a ser considerada a base de sua prosperidade (FOUCAULT, 2008a). A partir de então, o corpo feminino - lugar da gestação do futuro da nação - passou a se tornar, como nunca antes, foco dos investimentos médicos. Assim, a idéia de normalidade feminina atrelou-se ao que foi considerado o principal objetivo da mulher na república: gerar cidadãos saudáveis e educados. A função de boa mãe, esposa fiel e educadora virtuosa de seus filhos tornou-se não apenas o ideal feminino, mas passou a ser também considerado como o maior garantidor de sua saúde (DORLIN, 2006). Vale dizer, o desvio da norma de uma mulher ganhou contornos de calamidade, já que a doença dele decorrente, além de tomar o corpo da mulher, impedia que ela gerasse uma prole sã, onerando os cofres públicos, a sociedade, no nível da individualidade e da coletividade, e ameaçando o futuro da nação.

Neste sentido, os novos referenciais teóricos da psiquiatria organicista alemã, ainda que fossem voltados para aproximar a sua cientificidade da medicina geral, enfatizando fatores como hereditariedade, anatomia e fisiologia, e se proclamassem voltados para o orgânico, mantiveram presente o caráter moral do processo de internação, centrados que estavam nos vestígios da inadaptação social, que ganhava cores cada vez mais ameaçadoras para a sociedade. Como nos propõe Dorlin, "o gênero constrói a política e a política constrói o gênero" (2006, p. 6, trad. nossa). E podemos acrescentar a essa equação, a loucura também. 


\section{Referências Bibliográficas Fontes Primárias}

AUSTREGÉSILO, A. Novas concepções sobre histeria. Archivos Brasileiros de Psychiatria Neurologia e Medicina Legal, Rio de Janeiro, n. 1 e 2, p. 52-66, 1908. In: FACCHINETTI, C. (Coord.). Base de Dados Psi-coc. Rio de Janeiro. Casa de Oswaldo Cruz, 2008. Disponível em: DEPES-Coc/Fiocruz.

Hysteria e syndromo hysteroide. Archivos Brasileiros de Psychíatria Neurologia e Medicina Legal, Rio de Janeiro, n. 1 e 2, p. 59-77, 1909. In: FACCHINETTI, C. (Coord.). Base de Dados Psi-coc. Rio de J aneiro. Casa de Oswaldo Cruz, 2008. Disponível em: DEPES-Coc/Fiocruz. BOTELHO, A. Estados mixtos de psychose maníaco-depressiva. Arquivos Brasileiros de Neuriatria e de Psiquiatria, n. 2, p. 105-112, 1929. In: FACCHINETTI, C. (Coord.). Base de Dados Psi-coc. Rio de Janeiro. Casa de Oswaldo Cruz, 2008. Disponível em: DEPES-Coc/Fiocruz.

BRASIL. Decreto n. 5.148-A, de 10 de janeiro de 1927. Reorganiza a Assistência a Psicopatas no Distrito Federal. 10 jan 1927.

BRASIL. Decreto n. 17.805, de 23 de maio de 1927. Aprova o regulamento para a execução dos serviços para a Assistência a Psicopatas no Distrito Federal. 23 de maio 1927.

CASTELLO, A. V. Relatório do Ministério da Justiça e Negócios Interiores (1927). Rio de Janeiro: I mprensa Nacional, 1930. In: FACCHINETTI, C. (Coord.). Base de Dados Psi-coc. Rio de Janeiro. Casa de Oswaldo Cruz, 2008. Disponível no DEPES-Coc/Fiocruz.

CORRÊA, R. C. Relatório do Ministério da Justiça e Negócios Interiores (1911). Rio de Janeiro: I mprensa Nacional, 1912. In: FACCHINETTI, C. (Coord.). Base de Dados Psi-coc. Rio de Janeiro. Casa de Oswaldo Cruz, 2008. Disponível em: DEPES-Coc/Fiocruz.

FREITAS, U. H. Relatório do Ministério da Justiça e Negócios Interiores (1913). Rio de Janeiro: I mprensa Nacional, 1915. In: FACCHINETTI, C. (Coord.). Base de Dados Psi-coc. Rio de Janeiro. Casa de Oswaldo Cruz, 2008. Disponível em: DEPES-Coc/Fiocruz.

KEHL, R. A Inteligência da Mulher. O J ornal. 30/06/1920. Caixa 07, livro 01. Acervo Renato Kehl - DAD - COC/Fiocruz.

Quer Casar? Pois Consulte o Médico Primeiro! O esforço da Eugenia para Salvar a Raça-"Como Escolher uma Boa Esposa!". O Globo, 08/02/1926. Caixa 1, maço 1. Acervo Renato Kehl - DAD - COC/Fiocruz.

- Civilizando O Amor Para Garantia Dos Lares E Regeneração E Defesa Da Nacionalidade - o exame pré-nupcial e o seu valor eugênico, $\mathbf{0}$ Globo. 02/03/1926, p. 1-16. Acervo Renato Kehl - DAD - COC/Fiocruz.

LIVRO DE OBSERVAÇÃO. Pavilhão de Observação do Hospício Nacional. (IPUB/UFRJ). 1906.

LIVRO DE OBSERVAÇÃO. Pavilhão de Observação do Hospício Nacional. (IPUB/UFRJ). 1930.

LOPES, I. C. Das curas tardias em psiquiatria. Arquivos Brasileiros de Neuriatria e de Psiquiatria, Rio de Janeiro, II-III trimestres. pp.75-80, 1927. In: FACCHINETTI, C. (Coord.). Base de Dados Psi-coc. Rio de Janeiro. Casa de Oswaldo Cruz, 2008. Disponível em: DEPES-Coc/Fiocruz.

PEIXOTO, A. A loucura maníaco-depressiva. Archivos Brasileiros de Psychiatria, Neurologia e Sciencias Affins, Rio de Janeiro, n. 1, p. 3346, 1905. 
PORTO-CARRERO, J. P. Psicanálise de uma civilização. Rio de Janeiro: Editora Guanabara: Waissman Koogan Ltda., 1930a.

PORTO-CARRERO, J. O sexo e a Cultura. Archivos Brasileiros de Hygiene Mental, n. 5, p. 167-176, 1930b. In: FACCHINETTI, C. (Coord.). Base de Dados Psi-coc. Rio de Janeiro. Casa de Oswaldo Cruz, 2008. Disponível em: DEPES-Coc/Fiocruz.

PUECH, L. M. R. Ginecologia e alienação mental. Archivos Brasileiros de Psychiatria, Neurologia e Sciencias Affins, n. 3 e 4, p. 352-376, 1907. In: FACCHINETTI, C. (Coord.). Base de Dados Psi-coc. Rio de Janeiro. Casa de Oswaldo Cruz, 2008. Disponível em: DEPES-Coc/Fiocruz.

ROXO, H. Hysteria. Archivos Brasileiros de Psychiatria Neurologia e Sciencias Affins, Rio de Janeiro, n. 2, p. 139-148, 1906. In: FACCHINETTI, C. (Coord.). Base de Dados Psi-coc. Rio de Janeiro. Casa de Oswaldo Cruz, 2008. Disponível em: DEPES-Coc/Fiocruz.

ROXO, H. Ideas modernas sobre hysteria. Arquivos Brasileiros de Neuriatria e de Psiquiatria, n. 1, p. 9-15, 1929. In: FACCHINETTI, C. (Coord.). Base de Dados Psi-coc. Rio de Janeiro. Casa de Oswaldo Cruz, 2008. Disponível em: DEPES-Coc/Fiocruz.

SANTOS, C. M. P. Relatório do Ministério da Justiça e Negócios Interiores (1915). Rio de Janeiro: I mprensa Nacional, 1916. In: FACCHINETTI, C. (Coord.). Base de Dados Psi-coc. Rio de Janeiro. Casa de Oswaldo Cruz, 2008. Disponível em: DEPES-Coc/Fiocruz.

SEABRA, J. Relatório da Comissão de Inquérito sobre as condições da Assistência a Alienados no Hospício Nacional e colônias da Ilha do Governador (1902). Rio de Janeiro: I mprensa Nacional, 1903. Anexo B. In: FACCHINETTI, C. (Coord.). Base de Dados Psi-coc. Rio de Janeiro. Casa de Oswaldo Cruz, 2008. Disponível em: DEPES-Coc/Fiocruz.

\section{Fontes Secundárias}

ARACY, A. Tarsila: sua obra e seu tempo. São Paulo: Ed.34 / Edusp, 2003. BENCHIMOL, J. L. Pereira Passos: um Haussmann Tropical. A renovação urbana do Rio de Janeiro no início do século XX. Secretaria Municipal de Cultura, Turismo e Esporte; Departamento Geral de Documentação e Informação Cultural, Rio de Janeiro, 1990.

BERRIOS, G. Classificações em psiquiatria: uma história conceitual. Revista de Psiquiatria Clínica, São Paulo, v. 35, n. 3, p. 1 13-127, 2008.

BIRMAN, J. A cena constituinte da psicose maníaco-depressiva no Brasil. Revista História, Ciência, Saúde Manguinhos, Rio de Janeiro, Fundação Oswaldo Cruz. Casa de Oswaldo Cruz, v. 17, supl. 2, p. 345-372, 2010.

BORELLI, A. Matei por amor: representações do masculino e do feminino nos crimes passionais. São Paulo: Celso Bastos Editor, 1999.

BULMER-THOMAS, V. As economias latino-americanas, 1929-1939. In: BETHELL, L. (Org.). História da América Latina - A América Latina após 1930: economia e sociedade - vol. VI. São Paulo, Ed. da USP / Imprensa Oficial; Brasília, FUNAG, 2005.

CANGUILHEM, G. O normal e o patológico. Rio de Janeiro: Forense Universitária, 1990.

CAPONI, S. Emil Kraepelin y e problema de la degeneración. Revista História, Ciência, Saúde Manguinhos, Rio de Janeiro, Fundação Oswaldo Cruz, Casa de Oswaldo Cruz, v. 17, supl. 2, p. 475-494, 2010. 
COSTA, J. F. História da Psiquiatria no Brasil. Rio de Janeiro: Garamond, Fichamento: Heloisa Serzedello Corrêa, 2007.

CUPELLO, P. Loucura e Gênero no Hospital Nacional de Alienados (19201930). Relatório Final de Pesquisa de Iniciação Científica. FAPERJ, 2010.

DORLIN, E. La Matrice de la race. Généalogie sexuelle et coloniale de la Nation française, Paris, Editions La Découverte, 2006.

ENGEL, M. Delírios da Razão: Médicos, Loucos e Hospícios. Rio de Janeiro, 1830-1930. Rio de Janeiro: Fiocruz, 2001.

ESPÍRITO SANTO, A. A.; PEREIRA, V. F. S.; JACÓ-VILELA, A. M. Medicina Legal nas teses da Faculdade de Medicina do Rio de Janeiro (1830-1930) - o encontro entre Medicina e Direito, uma das condições de emergência da Psicologia Jurídica. I nterações, v. 10, p. 9-34. São Paulo: 2005.

FACCHINETTI, C.; VENANCIO, A. T. A. Entre a psicanálise e a degenerescência: sexualidade e doença mental no início do século XX no Brasil. Revista Latinoamericana de Psicopatologia Fundamental, ano IX, n. 1, p. 151-161, 2006.

FACCHINETTI, C.; CUPELLO, P.; EVAGELISTA, D. Arquivos Brasileiros de Psiquiatria, Neurologia e Ciências Afins: uma fonte com muita história. Revista História, Ciência, Saúde Manguinhos, Rio de Janeiro, Fundação Oswaldo Cruz. Casa de Oswaldo Cruz, v. 17, supl. 2, p. 527-535, 2010a.

FACCHINETTI, C.; RIBEIRO, A.; CHAGAS, D.; REIS, C. No Labirinto das Fontes do Hospício Nacional de Alienados. Revista História, Ciência, Saúde Manguinhos, Rio de Janeiro, Fundação Oswaldo Cruz. Casa de Oswaldo Cruz, v. 17, supl. 2, p. 733-768, 2010b.

FACCHINETTI, C. Júlio Pires Porto-Carrero: A psicanálise como ferramenta para a "Idade de Ouro" no Brasil. In: HOCHMAN, G; LIMA, N. T. (Orgs.). Médicos I ntérpretes do Brasil e da sociedade brasileira/ A Medicina interpreta o Brasil, Rio de Janeiro, Ed. Fiocruz, 2011, no prelo.

FOUCAULT, M. A Arqueologia do saber. Rio de Janeiro: Forense Universitária, 1986.

. Vigiar e punir: nascimento da prisão. Petrópolis, Vozes, 1987.

O Poder Psiquiátrico. In: Resumo dos cursos do Collège de

France ( 1970-1982). Rio de Janeiro: Jorge Zahar Ed., 1997.

. Os Anormais: curso no Collège de France (1974-1975). São

Paulo: Martins Fontes, 2001.

Microfísica do Poder. Rio de Janeiro: Graal, 2004, 19 edição.

Nascimento da biopolítica: curso dado no collège de France (1978-1979). São Paulo: Martins Fontes, 2008.

FOUCAULT, M. Segurança, Território, População. Curso dado no College de France (1977-1978). Trad. Eduardo Brandão. São Paulo: Martins Fontes, 2008a.

HAHNER, J. E. Emancipação do Sexo Feminino: a luta pelos direitos da mulher no Brasil, 1850 - 1940. Florianópolis: Editora Mulheres, 2003.

LIMA, N. T.; HOCHMAN, G. Condenado pela raça, absolvido pela medicina: o Brasil descoberto pelo movimento sanitarista da Primeira República. In: MAIO, M. C.; SANTOS, R. V. (Orgs.). Raça, ciência e sociedade. Rio de Janeiro, Fiocruz, p. 23-40, 1996. 
MACEDO, E. D. V. Uma luta justa e elegante: os feminismos conflitantes de Bertha Lutz e Maria Lacerda de Moura na década de 1920. In: Gênero, v. 3, n. 2. Eduff, 2000.

MACHADO, R.; LOUREIRO, A.; LUZ, R.; MURICY, K. Danação da norma: medicina social e constituição da psiquiatria no Brasil. RJ: Edições Graal, 1978.

MALUF, M.; MOTT, M. L. Recônditos do mundo feminino. In: NOVAIS, F. A. História da vida privada no Brasil. São Paulo: Companhia das Letras, 1998, p. 367-422.

MUÑOZ, P. F. N. Degeneração Atípica: uma incursão ao arquivo de Elza. 2010. 188f. Dissertação (Mestrado) - Programa de Pós-Graduação em História das Ciências e da Saúde. Casa de Oswaldo Cruz, Rio de Janeiro.

NEVES, M. S. O grande Mal no Cemitério dos Vivos. Revista História, Ciência, Saúde Manguinhos, Rio de Janeiro, Fundação Oswaldo Cruz. Casa de Oswaldo Cruz, v. 17, supl. 2, p. 293-309, 2010.

NUNES, S. A. Histeria e psiquiatria no Brasil na primeira República. Revista História, Ciência, Saúde Manguinhos, Rio de Janeiro, Fundação Oswaldo Cruz. Casa de Oswaldo Cruz, v. 17, supl.2, p. 373-390, 2010.

ODA, A. G. R.; DALGALARRONDO, P. Juliano Moreira: um psiquiatra negro frente ao racismo científico. Revista Brasileira de Psiquiatria, v. 22, n. 4, p. 178-179, 2000.

PEREIRA, C. S. C. Da Loucura à alienação mental: o Hospício Nacional de Alienados. Relatório Final de Pesquisa, apoio FIOCRUZ, 2006.

PORTOCARREIRO, V. Ciências da vida: de Canguilhem a Foucault. Rio de Janeiro: Editora Fiocruz, 2009.

REIS, J. R. F. De pequenino é que se torce o pepino: a infância nos programas eugênicos da Liga Brasileira de Higiene Mental. Revista História, Ciência, Saúde Manguinhos, p. 135-157, 2000.

ROSENBERG, C. Framing disease: illness, society and history. In: ROSENBERG, C.; GOLDEN, J. (Eds.). Framing disease: studies in cultural history. New Brunswick: Rutgers University Press, 1992, p. 305-318.

SANTOS, L. A. C. O pensamento sanitarista na Primeira República: Uma ideologia de construção da nacionalidade. Revista de Ciências Sociais, Rio de Janeiro, v. 28, n. 2, p. 193-210, 1985.

SCOTT, J. W. Prefácio a Gender and Politics of History. Cadernos Pagu: desacordos, desamores e diferenças. Campinas: Núcleo de Estudos de Gênero/ UNICAMP, v. 3, p. 11-27, 1994.

SINGER, P. O feminino e o feminismo. In: SINGER, P., BRANDT, V. C. (Orgs.). São Paulo: o povo em movimento. Petrópolis: Vozes, 1980.

SOUZA, V. Em nome da raça: a propaganda eugênica e as idéias de Renato Kehl nos anos 1910 e 1920. Revista de História Regional, p. 29-70, 2006.

TRILLAT, E. História da histeria. São Paulo: Ed. Escuta, 1991.

VENANCIO, A. T. A. Ciência psiquiátrica e política assistencial: a criação do Instituto de Psiquiatria da Universidade do Brasil. Revista História, Ciência, Saúde Manguinhos, v. 10, n. 3, p. 883-900, 2003. 


\section{Fontes da I nternet}

Arquivos de Múltiplos Idiomas. Joseph Babinski. Disponível em: <http://www.worldlingo.com/ma/enwiki/pt/Joseph_Babinski>. Acesso em: 25 Abr. 2011.

GONÇALVES, M. S. Os caminhos da loucura na segunda metade do século $\mathrm{XIX}$, no Rio de Janeiro. Anais do III Congresso Internacional de Psicopatologia Fundamental. IX Congresso Brasileiro de Psicopatologia Fundamental Pathos: violência e poder, Niterói. Associação Universitária de Pesquisa em Psicopatologia Fundamental, 2008. Disponível em: http://www.fundamentalpsychopathology.org/8_cong_anais/MR_34a.pdf.

Acesso em: 19 Abr. 2011.

ODA, A. M. G. R.; PICCININI, W. Dos males que acompanham o progresso do Brasil: a psiquiatria comparada de Juliano Moreira e colaboradores. Revista Latinoamericana de Psicopatologia Fundamental, São Paulo, v. 8, n. 4, p. 788-793, dez. 2005. Disponível em: <http://www. fundamentalpsychopathology.org/art/v08_04/historia.pdf>. Acesso em: 19 Abr. 2011.

PICCININI, W. J. História da Psiquiatria. Adauto Junqueira Botelho: notas biográficas. Disponível em:

<http://www.polbr.med.br/ano09/wal0209.php>. Acesso em: 06 Abr.

2011.

PONTES, H. Vida e obra de uma menina nada comportada: Pagu e o Suplemento Literário do Diário de S. Paulo. Cadernos Pagu, Campinas, n. 26, June 2006.2 Disponível em: <http://www.scielo.br/scielo.php?script=sci_arttext\&pid=S0104$83332006000100017 \& \mathrm{ng}=\mathrm{en \& nrm}=$ iso >. Acesso em: 20 Abr. 2011.

TEIVE, H. A. G.; SÁ, D.; SILVEIRA NETO O.; SILVEIRA O. A.; WERNECK L.C. “Professor Antonio Austregésilo: o pioneiro da neurologia e do estudo dos distúrbios do movimento no Brasil". Arquivos de Neuro-Psiquiatria. 1999, v. 57, n. 3, p. 898-902. Disponível em: <http://www.scielo.br/scielo.php?script=sci_arttext\&pid=S0004-

282X1999000500030>. Acesso em: 19 Abr. 2011.

\section{Endereço para correspondência}

Cristiana Facchinetti

FIOCRUZ, Depto. de Pesquisa, Av. Brasil, 4036, sala 400, Manguinhos, CEP $21040-$ 361, Rio de Janeiro-RJ, Brasil

Endereço eletrônico: cfac@fiocruz.br

Priscila Céspede Cupello

Rua Haia, 255, Tauá, Ilha do Governador, CEP 21920-180, Rio de Janeiro-RJ, Brasil

Endereço eletrônico: cupello.priscila@gmail.com

Recebido em: 28/03/2011

Reformulado em: 03/06/2011

Aceito para publicação em: 07/06/2011

Acompanhamento do processo editorial: Ana Maria Jacó-Vilela 


\section{Notas}

* Doutora em teoria psicanalítica (UFRJ), pesquisadora e professora do Programa de Pós-Graduação em História das Ciências e da Saúde da Casa de Oswaldo Cruz/Fiocruz.

** Mestranda do Programa de Pós-Graduação em História da Ciência e da Saúdecoc/Fiocruz.

${ }^{1}$ O Hospício Pedro II foi proposto no ato solene de coroação de Pedro II como um dos sinais da modernização e civilização da nação nos trópicos. Apesar do Decreto ser de 1841, o HPII só foi fundado em 1852 (apud GONÇALVES, 2008). Ele teve seu nome mudado algumas vezes. Depois da proclamação da República passou a ser chamado de Hospício Nacional de Alienados, mudando de nome em 1911 para Hospital Nacional de Alienados. Em 1927 passou a se chamar de Hospital Nacional de Psicopatas (ver decreto 5138-A de 1927).

${ }^{2}$ Juliano Moreira (1873-1933), graduado pela Faculdade de Medicina da Bahia, assumiu a direção do Hospício Nacional de Alienados, em 26 de Março de 1903, tendo acumulado também o cargo de diretor Geral da Assistência a Alienados a convite do ministro dos Negócios Interiores J. J. Seabra, exercendo essa função até 1930. Moreira foi responsável por difundir o modelo kraepeliano de psiquiatria, junto com o grupo formado em seu entorno (ODA; DALGALARRONDO, 2000).

3“Somente em 1881, em uma nova reforma do ensino médico (decreto 3024), foi criada a cadeira de Clínica Psiquiátrica e Moléstias Mentais, interinamente ocupada pelo também catedrático de Medicina Legal à época, Dr. Nuno de Andrade, diretor médico do hospício" (ESPÍRITO SANTO; PEREIRA; JACÓ-VILELA, 2005, p. 13).

${ }^{4}$ Emil Kraepelin (1856-1926), considerado o pai da psiquiatria moderna, que estabeleceu as bases do que hoje entendemos por psiquiatria, manteve viva e intacta a ambição de higienistas do século XIX de pensar os problemas existenciais e sociais com categorias médicas e orgânicas (CAPONI, 2010, p. 476).

${ }^{5}$ Em 1927, Assistência a Alienados passou a ser denominada de Assistência a Psicopatas. O decreto 5138-A de 10 de janeiro de 1927 depôs sobre profilaxia e higiene, e fez com que os alienistas passassem a se chamar psiquiatras. (FACCHINETTI et al., 2010a). Além disso, a Assistência passou a abranger não apenas os alienados, mas todos aqueles em risco de sofrerem de desordens mentais.

${ }^{6}$ Para maiores informações sobre debates acerca do sanitarismo e higiene mental no Estado Republicando conferir: Lima e Hochman, 1996; Santos, 1985.

${ }^{7}$ Para informações sobre as discussões acerca da Liga Brasileira de Higiene Mental conferir: Costa, 2007; Reis, 2000.

${ }^{8}$ Para Canguilhem, o termo "normal" designou, a partir do século XIX, o protótipo da saúde orgânica ligado ao bem (apud PORTOCARRERO, 2009, p. 213).

${ }^{9}$ Entre as décadas de 1910 e 1940 , Kehl assumiu a propaganda eugênica como uma missão política e intelectual, o que Ihe rendeu o título de "pai da eugenia no Brasil", conforme se referia o escritor Monteiro Lobato. Foi editor de revistas e periódicos nacionais, entre eles o Boletim de Eugenia, que circulou no período entre 1929 a 1933. Em 1918, com a colaboração do médico Arnaldo Vieira de Carvalho e de um grande número de intelectuais paulistas, fundou a Sociedade Eugênica de São Paulo e, em 1931, a Comissão Central Brasileira de Eugenia (SOUZA, 2006).

${ }^{10}$ Júlio Pires Porto-Carrero (1887-1937) foi professor catedrático de medicina legal na Faculdade de Direito. Era considerado um dos grandes divulgadores da psicanálise, chegando a intitular-se de psicanalista na década de 20 , além de importante membro do movimento eugênico (FACCHINETTI, 2011, no prelo).

${ }^{11}$ Além das seções Morel e Esquirol, o Hospício Nacional contava, na década de 20, com as seções Pinel (para homens mantidos com recursos de DF), Calmeil (destinada aos homens pensionistas), Pavilhão Bourneville (destinado às crianças), Pavilhões Griesinger e Guinle (para mulheres e homens epilépticos, respectivamente), Pavilhões Francisco de Castro e Jobim (destinado às moléstias 
intercorrentes) e Pavilhão Alaor Prata e Sigaud (reservado aos tuberculosos) (apud CASTELLO, 1930).

${ }^{12}$ Antônio Austregésilo Rodrigues Lima (1876-1960) formou-se em 1899 na Faculdade de Medicina do Rio de Janeiro. Entre 1901 e 1909 foi indicado pela Congregação da Faculdade de Medicina como professor substituto de Clínica Médica, Patologia Interna e Clínica Propedêutica. Em 1912 foi designado pela congregação da Faculdade de Medicina do Rio de Janeiro, professor catedrático da recém fundada cadeira de Neurologia. Realizou várias viagens de estudos pela Europa, particularmente a França, onde frequentou os serviços de Babinski e Dejérine, entre outros (TEIVE et al., 1999).

${ }^{13}$ Henrique de Brito Belford Roxo (1877-1969) formou-se doutor pela Faculdade de Medicina do Rio de Janeiro, em 1900, sob orientação de João Carlos Teixeira Brandão (1854-1921). De 1901 a 1910 trabalhou na função de assistente no Pavilhão de Observação e como diretor do Pavilhão, primeiro interinamente e posteriormente como titular do cargo, mesmo após 1938, quando o Pavilhão passou a se chamar Instituto de Psiquiatria da UFRJ - IPUB (FACCHINETTI; VENANCIO, 2006).

${ }^{14} \mathrm{O}$ periódico, primeiro periódico brasileiro especializado em psiquiatria, mudou de nome ao longo do tempo: Archivos Brasileiros de Psychiatria, Neurologia e Sciencias Affins (1905-1907); dos Archivos Brasileiros de Psychiatria, Neurologia e Medicina Legal (1908-1918) e dos Archivos Brasileiros de Neuriatria e Psychiatria (1920-1957). Sobre sua história, vide Facchinetti et al. (2010a, p. 527-535).

${ }^{15}$ Joseph Babinski (1857-1932), recebeu seu grau médico da Universidade de Paris em 1884, sendo discípulo de Charcot em Salpêtrière. Após a morte de seu mestre, em 1893, foi trabalhar no Hôpital de la Pitié, onde se dedicou ao estudo clínico de neurologia. Nessa época, começou a fazer exames patológicos em casos de histeria, elaborando critérios para separar a histeria das demais doenças orgânicas, inventando assim o conceito de pithiatismo (J OSEPH BABINSKI, 2011). J ean-Martin Charcot (1829-1893), psiquiatria e renomado neurologista francês, cujas idéias ganharam adeptos em diferentes partes do mundo (TRILLAT, 1991). Segundo seus críticos, ele teria sido responsável pela produção de sintomas histéricos pelo uso corrente da hipnose. As críticas a seu trabalho abriram novos espaços de produção de saberes sobre o alienismo (FOUCAULT, 1997).

${ }^{16}$ Influenciados, igualmente pela leitura freudiana da histeria, já que é notório neste período a intensificação da apropriação das teorias psicanalistas no país (cf. FACCHINETTI, 2011, no prelo).

${ }^{17}$ Adauto Botelho (1895-1963) foi docente da Faculdade Nacional de Medicina e Catedrático da Faculdade de Ciências Médicas do Distrito Federal, e um dos fundadores do Sanatório Botafogo. Na gestão Henrique Roxo, como diretor do Pavilhão de Observação, foi assistente, chefe de laboratório, chefe de clínica da cátedra e substituto eventual do catedrático. Entre 1937 e 1945 foi o diretor do SNDM. (PICCININI, 2011).

${ }^{18} \mathrm{O}$ nome das pacientes são fictícios, a fim de respeitar o sigilo de informações pessoais. 